\title{
An approach towards integrated modelling of 3D geology and landslide susceptibility in the Lesser Himalaya of central Nepal
}

\author{
Prem Bahadur Thapa \\ Department of Geology, Tri-Chandra Multiple Campus, Tribhuvan University, Kathmandu, Nepal \\ (Email: geoscithapa@yahoo.com)
}

\begin{abstract}
An approach towards integrated modelling of 3D geology and landslide susceptibility was performed with the application of GOCAD and GIS. Rock unit outcrops and orientation vectors were utilised in 3D geological modelling (geomodelling) whereas landslides and their causative variables were evaluated in the susceptibility model. Occurrence of landslides in the modelling site is the direct result of major rainstorms (extreme weather events) and their spatial localisation is greatly controlled by slope gradients, structural aspect of geological settings, and human interventions. The probability of future landslides was predicted through statistical algorithms (multivariate technique of logistic regression) and modelling result was validated by computing success rate in which AUC value is $93.78 \%$ indicating the model is valid with prediction accuracy of 0.5 to 1 (total area) and confirming the selected variables have positive influence on landslide susceptibility. Finally, 3D geological and landslide susceptibility models were integrated to illustrate virtual reality of the scenario.
\end{abstract}

Keywords: GIS, GOCAD, 3D geological modelling, landslide, susceptibility, validation.

Received: January 15, 2014

Revision accepted: May 30, 2015

\section{INTRODUCTION}

Three Dimensional (3D) geological modelling deals the numerical description of geometry and properties of the subsurface. In recent years, geomodelling systems have been developed with high resolution $3 \mathrm{D}$ visualisation with respect to geometry as well as to property modelling capabilities in order to enable the construction and analysis of 3D geologic models in a way that general purpose Geographical Information System (GIS) and Computer Aided Design (CAD) systems simply cannot do (Mallet 1992, 2002). The 3D geological modelling has started to upgrade classical maps by providing a definite 3D description, and they are constructed by modelling geological features as surfaces which intersect according to rules that allow the visual representation of the geological features of interest (Mayoraz et al. 1992, Mallet 1997, de Kemp 1998, 1999; Jones et al. 2002, Mallet 2002, Lemon and Jones 2003, Galera et al. 2003). The 3D geological models are increasingly used in geo-hazard assessment (e.g. landslide susceptibility) to provide more detailed information about the spatial extent, temporal occurrence, triggers, and impacts of causative factors. Therefore, an effort towards integration of 3D geological and landslide susceptibility models has been made in the Lesser Himalaya of central Nepal.

The landslide susceptibility was analysed by assuming landslides will occur in the future because of the same conditions that produced them in the past (Varnes 1984, Carrara et al. 1991 ) and the susceptibility assessments can be used to predict the geographical location of future landslides (Chung and Fabbri 1999, Guzzetti et al. 2005). Understanding the role of individual factors controlling landslide location, geographical pattern, and spatial density is important to predict where landslides can occur in the future, i.e. to ascertain landslide susceptibility (Varnes 1984, Soeters and van Westen 1996, Guzzetti et al. 1999, van Den Eeckhaut et al. 2006). Qualitative and quantitative methods have been used in the process of creating landslide-susceptibility maps (Soeters and van Westen 1996, Aleotti and Chowdhury 1999, Guzzetti et al. 1999). The qualitative method was widely used during the late 1970s and the quantitative methods, however, became popular in the last few decades largely because of the numerical expressions of the relationship between controlling factors and landslides, assisted by the advances in GIS technology (Chung et al. 2002, van Westen and Lulie Getahun 2003, Bell and Glade 2004, van Westen et al. 2008). The general trend related to landslide assessments is the utilisation of GIS-based technology and the mathematical/statistical tools for modelling and simulation, have led to the growing application of quantitative techniques in many areas of the earth sciences (Carrara and Pike 2008). The GIS-based evaluations of landslide susceptibility have frequently applied the multivariate techniques of logistic regression models (Atkinson and Massari 1998, van Westen et al. 1997, Guzzetti et al. 1999, Dai and Lee 2002, Ohlmacher and Davis 2003, Baeza et al. 2010 etc.). 
The most appropriate landslide susceptibility prediction modelling between qualitative and quantitative descriptors is strictly related to the availability, quality and accuracy of data as well as resolution of the model and does not depend on the complexity level of the performed analysis (Cascini 2008). Existing methods have their advantages and disadvantages; due to the large spatial variability of the mechanical, hydrological and geometrical parameters involved in the equations (Burton et al. 1998, Terlien et al. 1995), application of well-known physically based methods (deterministic approach) developed by Hammond et al. (1992), Montgomery and Dietrich (1994) and Pack et al. (1998) is expensive in wide areas and so this kind of analysis is usually limited to small and relatively homogenous area which require detailed geotechnical and hydrogeological data. Thus, the current study has developed the statistical analysis of landslide prediction modelling which is particularly suited to determine landslide susceptibility over large and complex areas (e.g., Cardinali et al. 2002). The method has provided quantitative estimates of "where" landslides are expected, based on distinctive information on the distribution of past landslides and a set of thematic geo- environmental factors. The former becomes the dependent variable and the latter the independent variables for the model.

\section{SETTING OF THE AREA}

The modelling site for 3D geology and landslide susceptibility is located in the Lesser Himalaya of central Nepal and lies between the latitudes $27^{\circ} 37^{\prime}$ and $27^{\circ} 45^{\prime} \mathrm{N}$, and the longitudes $84^{\circ} 58^{\prime}$ and $85^{\circ} 07^{\prime} \mathrm{E}$ (Fig. 1). The site extends over an area of $210.4 \mathrm{~km}^{2}$ and is characterised by complex mountainous terrain with elevation ranging from 560 amsl to $2481 \mathrm{amsl}$. Agra Khola is the main draining river in study area.

Lithological and the structural setting control the geomorphology of the area, which features asymmetric slopes dissected by a dense, actively eroding stream network. The area exhibits highly rugged topography in the south whereas it is smooth in the north. The surficial materials reflect the bedrock and the materials on hill-slopes are mainly of residual soil and colluvium including slope debris. The residual soils occupy most of the area and have variable depths and areal extents. The colluviums are scattered in distribution. Deposition of

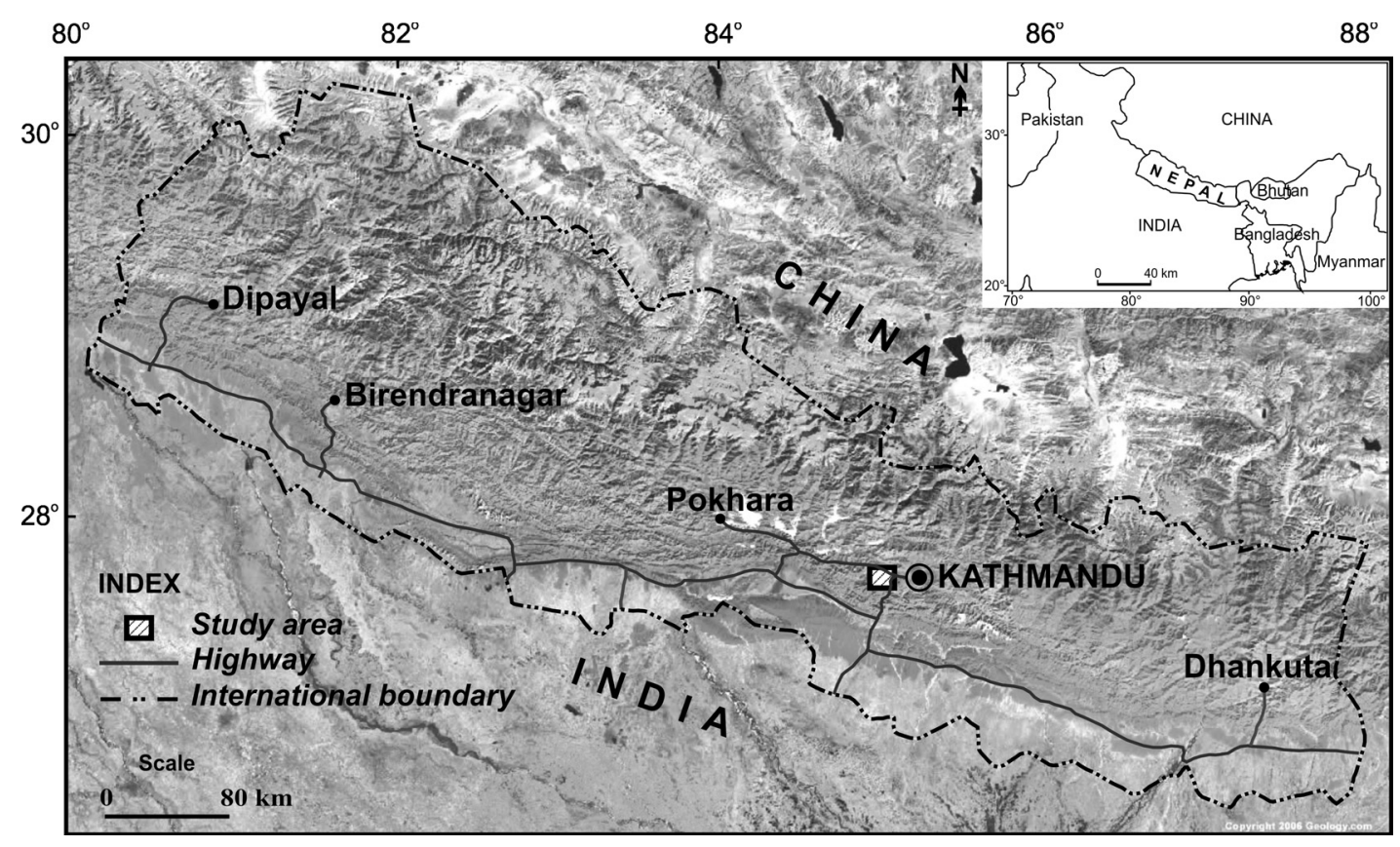

Fig. 1: Location map of the modelling site.

alluvial soils are found along the base slopes close to river valleys and are generally confined to fans developed downslope of the colluvial deposits and alluvium depths ranges from $2 \mathrm{~m}$ to $10 \mathrm{~m}$ thick.

The study area comprises six different lithological units that consisting of sedimentary, metamorphic and igneous rocks (Fig. 2). The outcropping rocks are predominantly of Precambrian to Palaeozoic low- to medium-grade metamorphic rocks such as meta-sandstones, slates, phyllites, marbles, quartzites and schists (Stöcklin and Bhattarai 1977). Limestone crops out in the eastern region whereas granite intrusion occurs in the western and southern parts (Fig. 2). The area is geo-dynamically active, represented by the closure of the Mahabharat Synclinorium. The attitude of strata (bedding or foliation) is variable; in general, strata in the southern belt are dipping $32-85^{\circ}$ due northeast to north and dipping $45^{\circ}-81^{\circ}$ due southwest in the northern belt. 


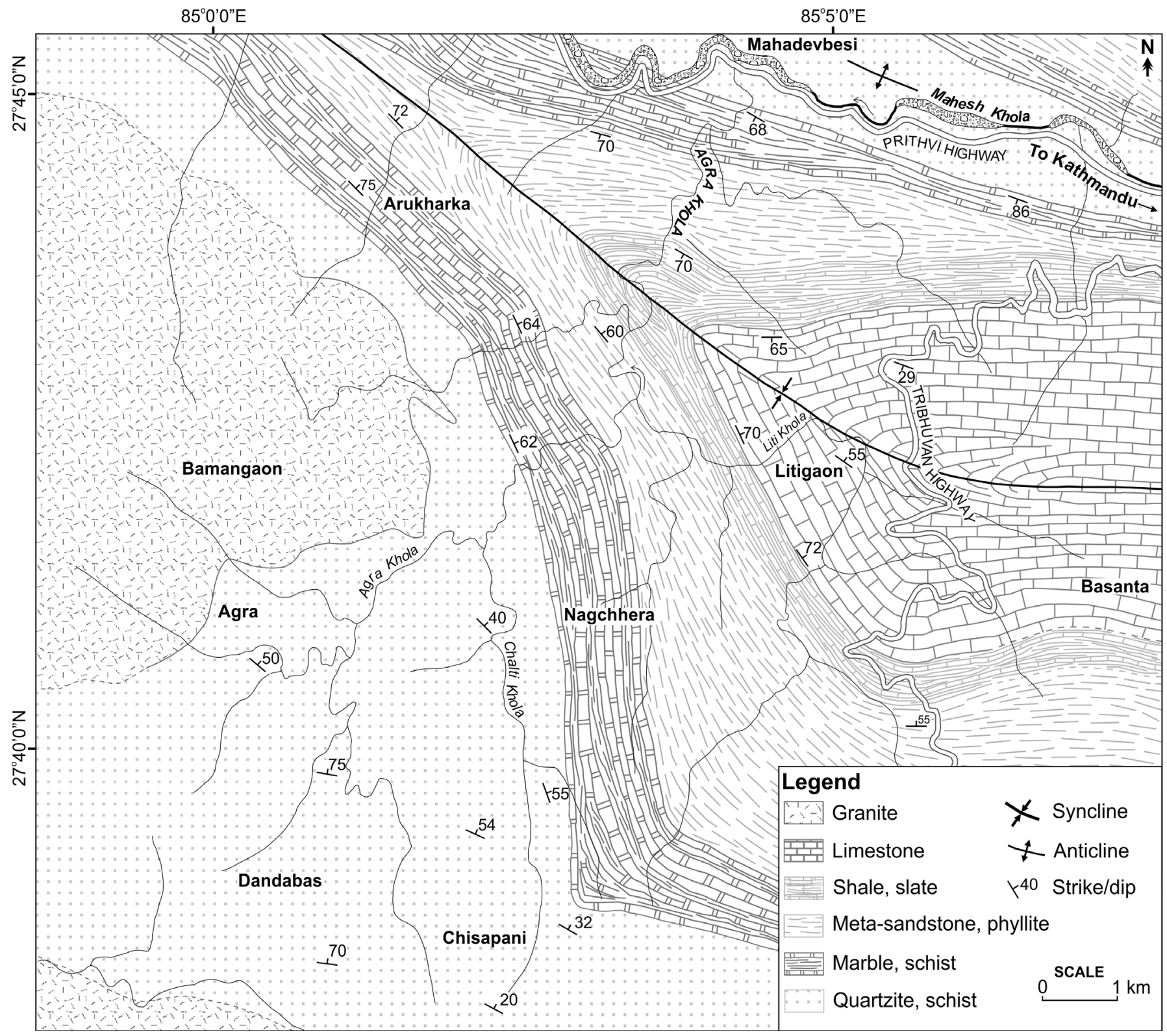

Fig. 2: Generalised geological map of the Lesser Himalaya, central Nepal (modified after Stöcklin and Bhattarai 1977).

\section{D GEOLOGICAL MODELLING}

The geological map has always been a central piece in geology but a map remains an incomplete representation, in particular when it comes to predict the nature of rocks below the earth's surface. 3D geological modelling is often performed to represent, and eventually better understand the geometric, topological, and physical properties of geological objects (Mallet 1992). 3D geomodel provides new information either visually or by performing quantitative analyses in the modelled geological objects. Mathematically and geometrically derived 3D geological model is important for volume and shape of the geological features, even for non-specialists, the model is self-explanatory. In addition, structural information and an appropriate extension of the major geological units of the area of interest (AOI) can be extracted from the geomodels.

\section{Model configuration}

Tools for 3D modelling mainly designed for data-rich environment, however many geological investigations are limited to only sparse data or poorly distribute data. This research has applied the innovative way to compute model using optimum available data which include lithological boundaries, representative cross section and orientation vectors (Fig. 3a). Considering nature of data, the model setup was made by means of implicit approach to interpolate the data and in which GOCAD workflow integrated model properties for determining the spatial locations/geometry.

ArcGIS functions were used to create spatial database. GIS shapefiles were imported in GOCAD as point or curve objects and converted into analytical format. Topographic 
surface was created from point set data of digital elevation model (DEM) and other imported geo-objects (outcrop boundary curves, orientation vector points) were projected vertically on it. $2 \mathrm{D}$ voxet of geological cross section was georeferenced and digitised in curves. The coordinates of an orientation vector $v=\left[v_{\mathrm{x}}, v_{\mathrm{y}}, v_{\mathrm{z}}\right]$ were implemented from the dip direction $\theta$ (azimuth) and dip $\phi$ angles through the following trigonometric formula (Eq. 1) (Sprague and de Kemp 2005):

$$
v=\left[\begin{array}{c}
\sin (\theta) \cdot \cos (\phi) \\
\cos (\theta) \cdot \cos (\phi) \\
\cos (\phi)
\end{array}\right]
$$

$3 \mathrm{D}$ vectors are convenient to display and manipulate (i.e. vector addition) and change of basis or other transformation can be applied easily. By controlling the representation in space of the orientation vectors, it may take advantage of a variety of interpolation schemes.

\section{Interpolation and model 3D}

Model configuration was performed by setting appropriate constraints by means of various GOCAD plugins, and then Discrete Smooth Interpolation (DSI) algorithm was run to compute rock strata geometry. The DSI optimizes all three spatial coordinates of mesh vertices and this method allows interpolating the functions of $\varphi$ the discrete model, like geometry or properties, while honouring a set of constraints
Ci (Mallet 1997). The algorithm converges towards a solution (Eq. 2);

$$
R^{*}(\varphi)=\sum_{\alpha \in \Omega} \mu(\alpha) \cdot R(\varphi \mid \alpha)+(\phi \cdot \varpi) \cdot \sum_{c \in C \approx} \varpi \cdot \rho(\varphi \mid c)
$$

where, $R(\varphi \mid \alpha)$ is the local roughness at node $\alpha, \rho(\varphi \mid c)$ is a constraint defined for node $\alpha, \mu$ is a stiffness coefficient, and $\varpi_{c}, \phi . \varpi$ are weight coefficients. This generic method allows the usage of heterogeneous data as constraints for the interpolation. It is always reproducible, on what primary data an interpolated object is based on. In GOCAD, iteration of DSI interpolation generates a smooth surface, the boundary of which coincides with lines representing the original boundary surface (Zehner 2011) and four stratigraphic bottom surfaces were obtained. In some cases, surface adjustment was also made locally by region interpolation or removing cross-over.

After generating all the surfaces of geological units, surfaces have to be selected to delimit top and base while outer borders of both surfaces are given by the area of interest. In order to model the main stratigraphic units, the DEM was used as top surface while the base is a surface with a constant depth about $2500 \mathrm{~m}$. A systematic sequence of steps has built the rock strata units from base to top and the operations are automatic or interactive with a possibility to select options to improve the modelling.

$3 \mathrm{D}$ volume model was constructed as a stratigraphic voxet (Fig. 3b) and finally 3D geological model of the study

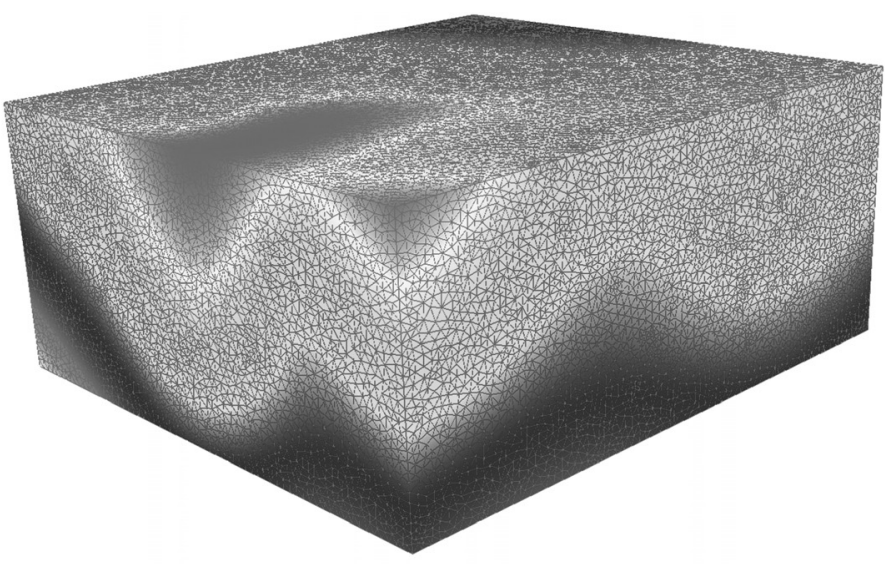

(b)

Fig. 3: 3D geological modelling (a) model configuration and extracted surfaces (b) computed 3D model.

area was visualised in a view that has displayed the internal synclinorioum structure and intrusive bodies. Dynamic visualisation is possible from slicing tool by moving in all directions.

\section{LANDSLIDE SUSCEPTIBILITY MODELLING}

The landslide susceptibility is the likelihood of a landslide occurring in an area with given local terrain attributes Brabb
(1984).Triggering factors (earthquake or extreme weather) and landslide inventory is the key information source for landslide susceptibility modelling (Hervás et al. 2013). The information should give insight into the location, date, type, size, activity and causal factors of landslides as well as resultant damage. Therefore, weather event, landslides and damage consequences were assessed to model landslide susceptibility in the Lesser Himalaya of central Nepal. 


\section{Weather event and landslide inventory}

Extreme weather event of 19-21 July 1993 with the major cloudburst near the Tistung-Palung region occurred in the central Nepal (Fig. 4) and volume of maximum precipitation recorded within 24 hours in the nearest rain gauge of Tistung was $540 \mathrm{~mm}$ (DHM 1993). The high intensity rainfall had caused the large number of landslides, debris flows, and almost coincidental arrival of floods from various tributaries to the main course. The July 1993 landslide/flood disaster in central Nepal was the second major natural disasters that Nepal faced only five years after the 1988 eastern Nepal earthquake. By this disaster, five hundred thousand people were affected, about 1500 people died, 60,000 hectares $\left(600 \mathrm{~km}^{2}\right)$ of land were damaged, and numerous irrigation, transportation systems and other infrastructure were destroyed. Estimates place the losses from this single event at about 70 million US Dollar (Chhetri and Bhattarai 2001).

The main triggering factor of landslides and debris flows in the study area was torrential rain of about $70 \mathrm{~mm}$ (maximum) per hour within 3 consecutive days (Fig. 4, see hyetograph). A total period of 24 hours rainfall exceeding $400 \mathrm{~mm}$ had caused the occurrence of 229 landslides (polygons and points) within the modelling site and found to be spatially localised in the cloudburst region of 1993 (Fig. 4). The major slope failures of July 1993 event were seen at the uppermost catchment of the Agra Khola watershed which was one of the most affected watersheds in the central Nepal. The large deep-seated slides were found in the north-facing dip-slopes such as Chisapani and Chaubas villages (Fig. 5a), whereas shallow slides were observed on the counter dip-slopes and the area occupied by granite. Despite critical landslide hazardous situation, village roads are under construction that crossing the large slides and every year, new slides are initiated due to such human activity (Fig. 5b, c). Tilted trees can be seen up to now in the steep mountain slope of Chisapani-Chaubas area indicating the future instability (Fig. 5d). Within the study area only, the landslides due to cloudburst incidence of 1993 had caused 42 casualties and washed away a four span bridge located at Mahadevbesi of the Prithvi Highway (Fig. 5e). A temporary

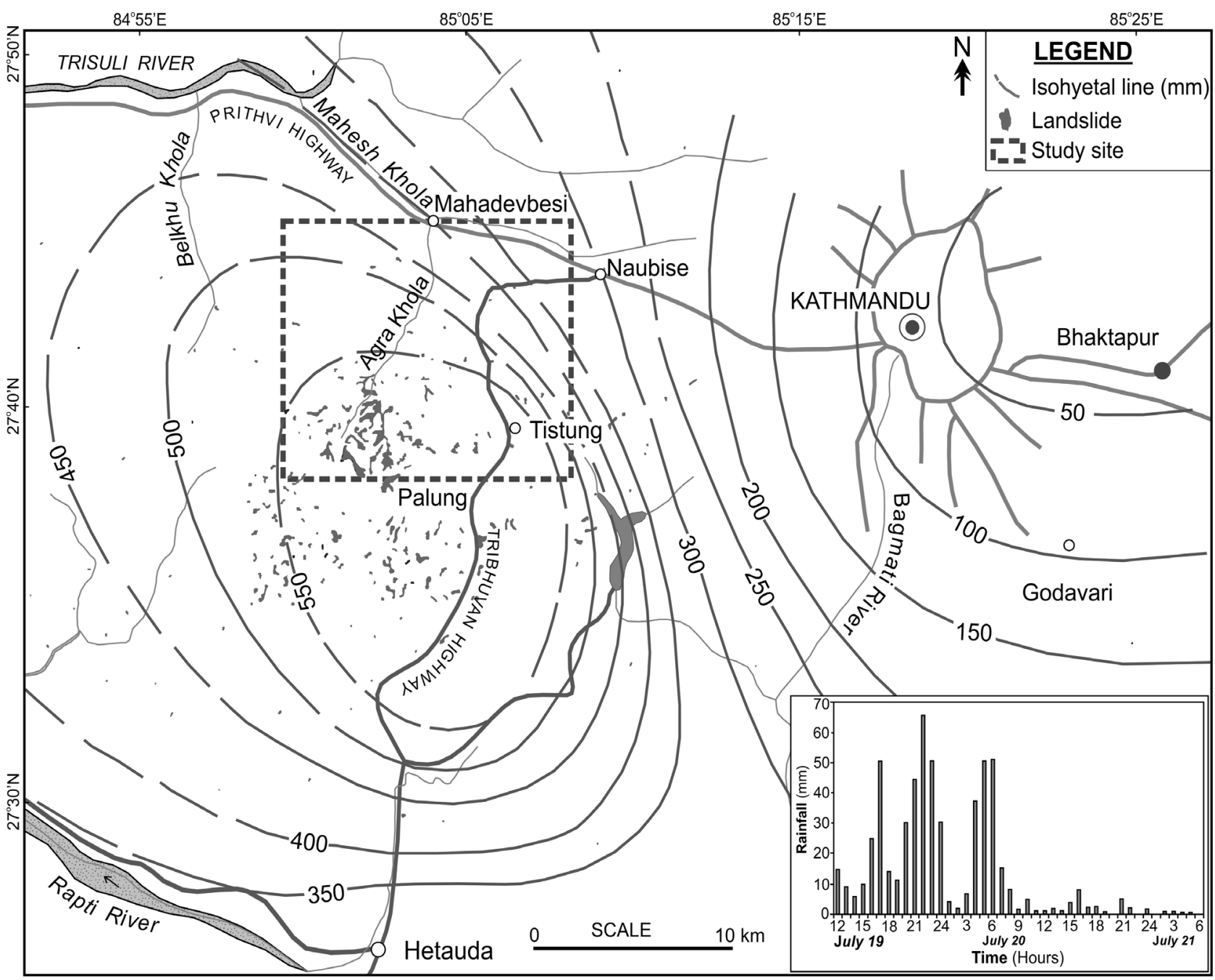

Fig. 4: Isohyetal map (24 hours) of the central Nepal during 19-21 July 1993 with showing landslide inventory from 1993 to 2013 and hyetograph of the rainfall event at Tistung Station (source: DHM, field visit and Department of Soil Conservation and Watershed Management). 


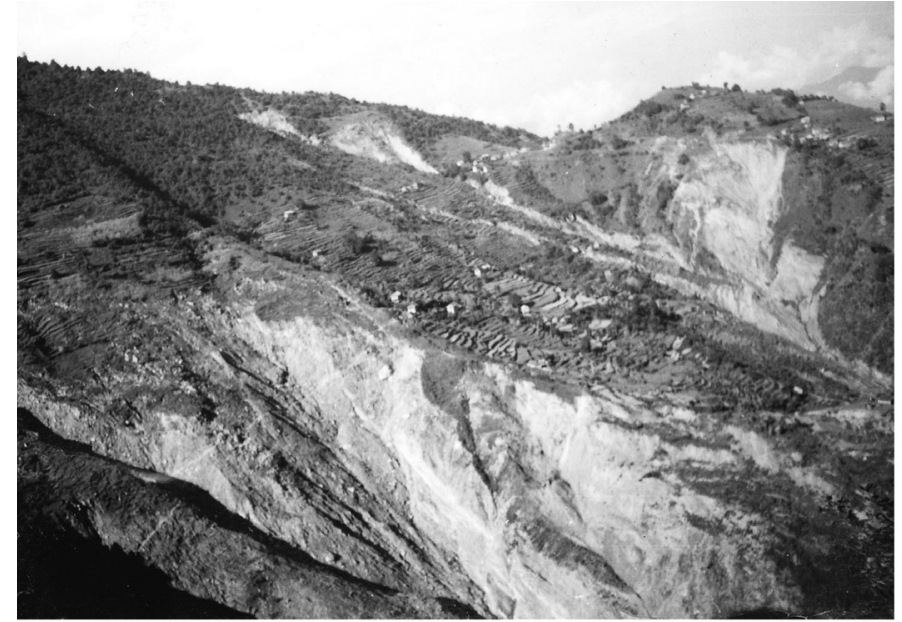

(a)

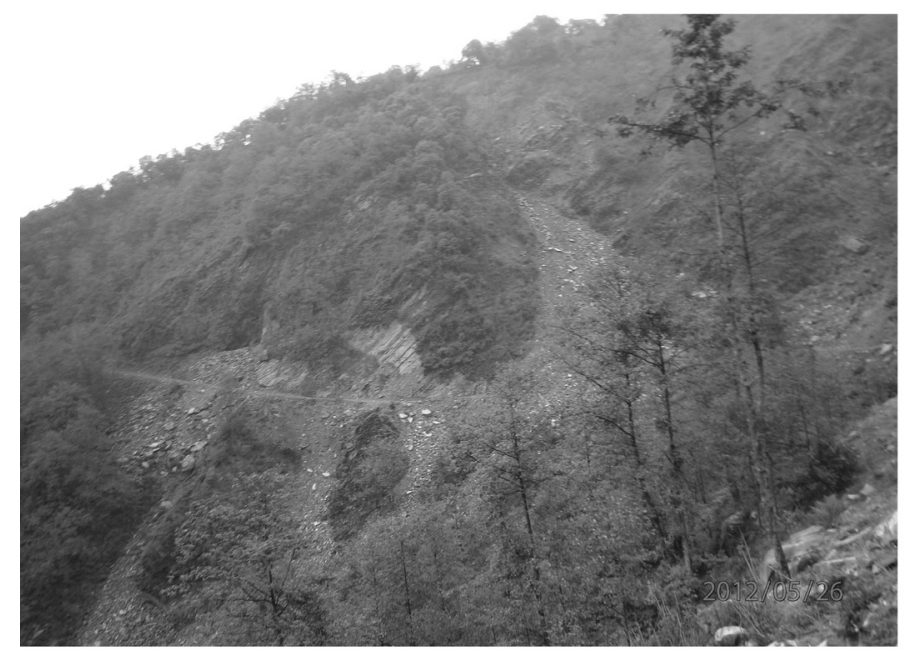

(c)

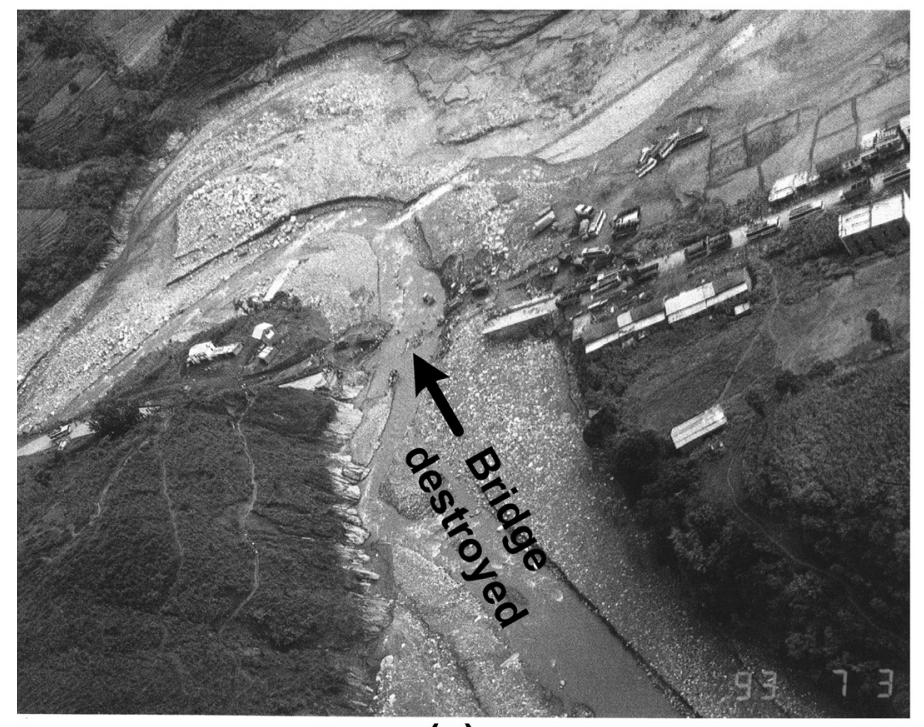

(e)

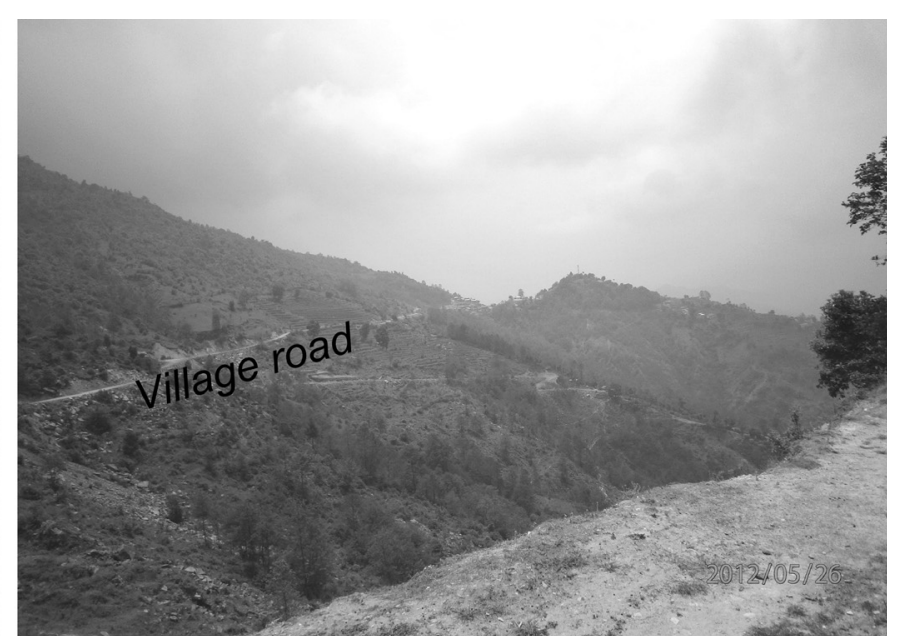

(b)

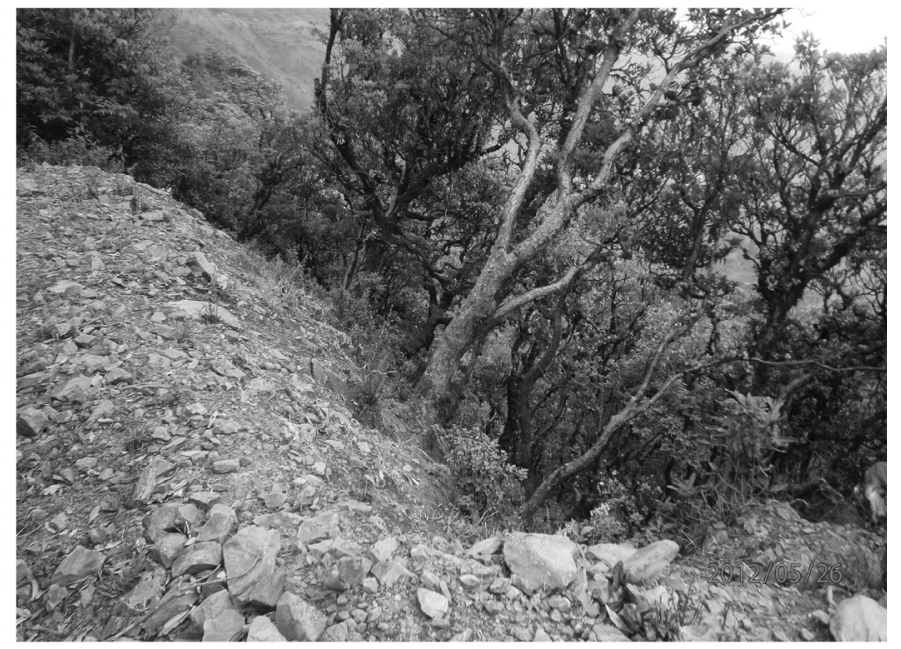

(d)

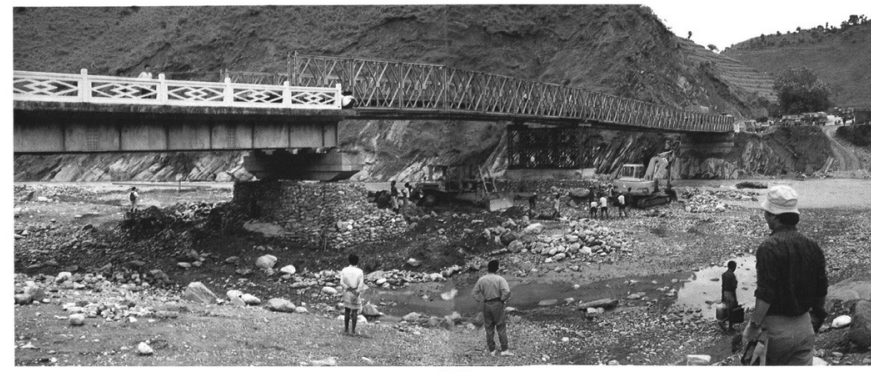

(f)

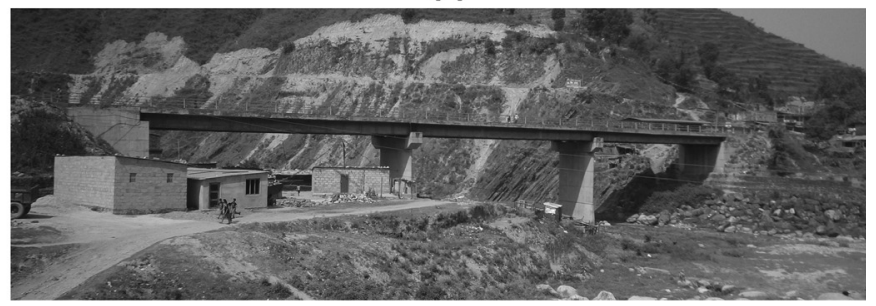

(g)

Fig. 5: Landslides occurrences and their consequences in the study area (1993-2013). (a) A huge landslide at Chisapani, July 1993 (b) Village roads are constructed within Chisapani Landslide despite of critical landslide risk, May 2012 (c) Activation of new slides in Chaubas Landslide, May 2012, (d) Tilted trees in the hill-slope indicating the future instability, May 2012 (e) Washed out bridge site at Mahadevbesi, 20 July 1993 (f) A bailey bridge was constructed immediately after the landslides and flood disaster of 1993, and (g) Reconstructed concrete bridge at present. 
bailey bridge was installed immediately after washed away (Fig. 5f) and then a new bridge has been reconstructed in the same location with elevated height and long length than the destroyed ones (Fig. 5g).

\section{Acquisition of modelling variables}

Landslides and their contributing variable maps were acquired as digitized layers of field-surveyed maps or derivative layers by spatial analysis which comprise the terrain, geo-material, and other relevant parameters that have been linked to slope failures. The database included the landslides inventory and landslide causing variable maps. The data set of landslide inventory is an indispensable data source representative of samples of landslide presence that may represent single or multiple events (Chacón et al. 2006). Geological and geomorphological variables that were obtained from different sources: existing digital data and field surveying (Fig. 6). Thus, the spatial data have been gathered and manipulated automatically or semi-automatically.

Terrain features and derivatives: spot height and contour values of topographic map were used to generate Triangulated Irregular Network (TIN) and from which the DEM was generated by using spatial function in GIS. Morphometrical and hydrological parameters were extracted from the DEM using neighbourhood operations (Fig. 6). Slope angle and slope aspect are important derivative layers for the landslide activity. Furthermore, drainage lines and polygons were corrected with existing digital data as well as in the field and then ranked into different morphometric orders (1-5) according to Strahler classification, and proximity analysis was performed to evaluate the effect of drainage (Fig. 6).

Field-surveyed thematic layers: Vector layers of fieldsurveyed physical variables were lithology, slope complexity, engineering geology and land use maps (Fig. 6). The generalised lithological map was prepared from geological mapping in the field. The lithological map was converted into a structural complexity map by utilising rock strata attitude (dip direction/dip amount) and slope (angle/aspect). Engineering geological transformation has involved the unification of distinctive geo-lithological information based on their engineering characteristics mainly from material strengths and spatial variation of geotechnical parameters. Information in the engineering geological map was represented in a discrete way, which consists of alluvium, colluvium, and residual soils. Soil depths were estimated in the field and two subclasses are considered: thin ( $1-3 \mathrm{~m}$ ) and thick (more than $3 \mathrm{~m}$ ) types. The rock slope or soil cover with a thickness of less than $1 \mathrm{~m}$ was included in the rocky terrain and categorised into low, medium, and high rock mass strength categories. The rock mass strength classification was based on measurement of intact rock strength and rock mass properties. The land use layer was classified into forest, shrub land, grassland, cultivated land and barren land. Facility map (e.g. road network) was obtained from an existing digital map and fieldwork verification.

Landslides in the model site were mapped $(1: 25,000$ scale) after the July 1993 event to 2013 with repeated visits in order to see any further changes. Large (172 to $\left.280000 \mathrm{~m}^{2}\right)$ landslides are mapped as polygon and small landslide patches were plotted simply as point features. The quality and reliability of the landslide distribution map should be considered high (Soeters and van Westen 1996), as the entire slope movements were directly identified in the field in order to define landslide types, soil characteristics, thickness of the failed material, soil depth and geology. It is presumed that preparation of the landslide database minimises the subjectivity and observational or measurement errors during the field studies.

All GIS data layers were geo-referenced in the Modified Universal Transverse Mercator (MUTM) coordinate system. Spatial data was entered via digitization of field surveyed data or directly from existing digital source. Editing digitized data, projecting and transforming, attribute assignment and verification were done after entering the map data. Once point, line and polygon features of landslides and related factors were created, topology was built and other relevant attributes were keyed in or imported from other digital databases (Fig. 6). Spatial extent of desired area under the analysis was obtained with the use of Geoprocesing Wizard.

Thematic vector layers were rasterized for analytical purposes and a grid resolution of $10 \mathrm{~m}$ was utilised for fully exploiting the detailed information. The grid format was considered optimum for this kind of process, as the sizes of the smallest landslide occurrence were represented in the analysis. Continuous attributes were discretised (Fig. 6) into relevant categories (for example, slope angle is reclassified in to 5 classes) according to geomorphic variations and site conditions. In establishing reclassification criteria for continuous variables, a compromise has been made between the need to have a limited number of classes which sufficiently represent the wide range of original values in each class. Finally, factors that influence landslides were extracted from the database.

\section{Modelling technique and result}

A multivariate technique of logistic regression was used to develop the landslide susceptibility model. The logistic regression is a mathematical modelling approach that can be used to describe the relationship of several independent variables to dichotomous dependent variable such as landslide (Kleinbaum 1994). In the process, an important aspect is the conversion of various nominal parameters (e.g., lithology, land use) to numeric values which was done through the creation of dummy variables matrix.

The GIS database was then exported to statistical software (SPSS) for computation of logistic regression equations. Quantitatively, the relationship between the landslide occurrence and its dependency on several variables can be expressed as (Eq. 3):

$$
\operatorname{Pr}(\text { event })=1 /\left(1+e^{-z}\right)
$$

where, $\operatorname{Pr}($ event $)$ is the probability of an event occurring. In the present situation, the $\operatorname{Pr}($ event $)$ is the estimated probability 


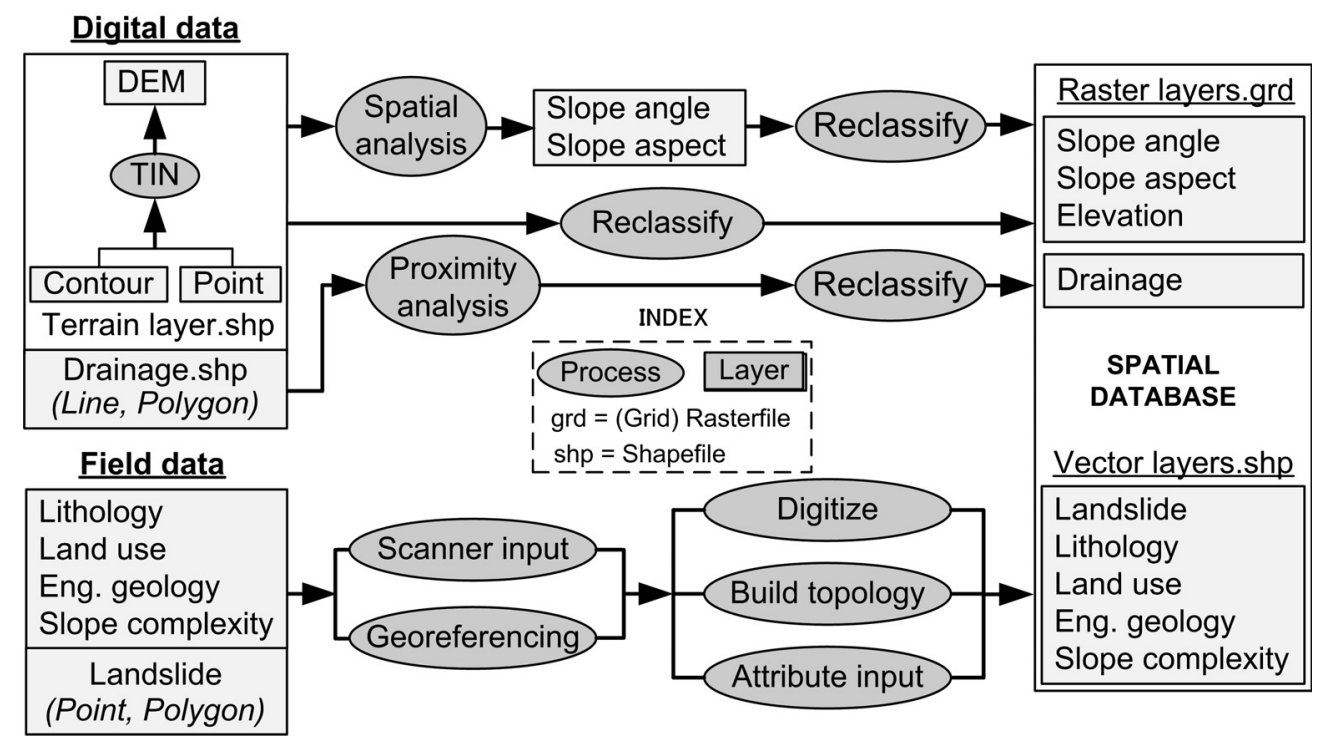

Fig. 6: Acquisition and development of landslide spatial database.

of landslide occurrence. As $Z$ varies from $-\infty$ to $+\infty$, the probability varies from 0 to 1 on an S-shaped curve. $Z$ is the linear combination (Eq. 4):

$$
Z=B_{0}+B_{1} X_{1}+B_{2} X_{2} \cdots+B_{n} X_{n}
$$

where, $B_{0}$ is the intercept and $B_{1}, B_{2}, \ldots B_{n}$ are the coefficients estimated from the sample data, which measure the contribution of independent variables $\left(X_{1}, X_{2}, \ldots, X_{n}\right)$.

In logistic regression analysis, the likelihood-ratio test was used for determining whether variables should be added to the model (forward inclusion or backward exclusion). Elevation and distance to drainage variable are removed from the model due to low significance values and other variables were taken into consideration for landslide susceptibility modelling. The final coefficients of logistic regression values for causative variables (Table 1) from SPSS were imported back into the GIS to calculate landslide susceptibility values. The results of the model have been optimised by adjusting the input variables interactively. The degree of landslide susceptibility is expressed in relative term from very low to very high susceptibility levels (5 categories) using natural junk break method with some adjustment of boundaries by overlying landslide map.

\section{Verification/validation of model}

In prediction modelling, the absolutely essential component is to verify/validate the results (Beguería 2006) so that it can be used to predict landslide-prone ground in further areas with similar physical factors related to landsliding. After the results of landslide susceptibility, the performance of the model and accuracy of result were evaluated by comparing the susceptibility map with the landslide distribution map. The comparison can be qualitative - for instance by a visual overlay - or quantitative, using different indices such as area of a class affected by landslides per total area of class (Süzen and Doyuran 2004, Yesilnacar and Topal 2005, Zhou et al. 2002), a confusion matrix (Carrara 1983, Carrara et al. 2003) or by using the Receiver Operating Characteristic (ROC) curve (Chung and Fabbri 2003, Fabbri et al. 2003).

In this study, the computed landslide susceptibility map was cross verified in the field and it is observed that the areas of high susceptible zones showed significant indications of slope instability marked by landslides, erosion, and subsidence. The field assessments have been extremely useful in calibrating the model, particularly in the identification and delineation of susceptibility category boundaries. Furthermore, quantitative validation was performed by intersecting between the prediction image and observed landslide locations to compute the number of occurred landslides with respect to susceptible values. These values were used to prepare the "success rate" because the success rate evaluates the degree of match between the predicted susceptibility levels in a given region, and the distribution of known landslides in the same region (Chung and Fabbri 2003, Guzzetti et al. 2005, Conoscenti et al. 2008). The success rate is also called internal validation (JiménezPerálvarez et al. 2011) and to obtain the success rate curve, the calculated landslide susceptibility values were sorted in descending order and then, the ordered values were divided into 100 classes with $1 \%$ cumulative intervals and plotted. The success rate plot was evaluated by computing Area Under the Curve (AUC) which was 0.9378 indicating the rate is $94.78 \%$ (Fig. 7). The value of AUC ranges from 0.5 to 1 . If the AUC value close to 1 , that means high accuracy of prediction model and if the AUC value close to 0.5 which indicates the inaccuracy of the model (Fawccett 2006). The verification of results showed the satisfactory agreement between presumptive hazard/susceptibility map and existing data on landslide locations (i.e. the causative variables selected are relevant and model performs successfully). The areas in high susceptible zones that are devoid of landslides indicate the probability of future landslides. 
Table 1: Calculated regression coefficients for landslide causative (independent) variables

\begin{tabular}{|c|c|c|c|}
\hline Causative variables & Coefficients & Causative variables & Coefficients \\
\hline Slope angle & & Engineering geological units & \\
\hline$<15$ & -0.22 & Thin soil $(1-3 \mathrm{~m})$ & -0.20 \\
\hline $15^{\circ}-25^{\circ}$ & 0.07 & Thick soil (>3 m) & -0.27 \\
\hline $25^{\circ}-35^{\circ}$ & 0.78 & Colluvium & -0.88 \\
\hline $35^{\circ}-45^{\circ}$ & 0.42 & Alluvium & 0.24 \\
\hline$>45^{\circ}$ & -0.15 & High Rock Mass Strength & -0.87 \\
\hline Slope aspect & & Medium Rock Mass Strength & 0.22 \\
\hline Flat & -0.39 & Low Rock Mass Strength & 1.42 \\
\hline North & 0.12 & Slope complexity & \\
\hline North East & 0.25 & Granitic slope & -1.66 \\
\hline East & 0.59 & Oblique slope & -0.35 \\
\hline South East & -0.12 & Dip-slope $\leq$ slope & 1.36 \\
\hline South & 0.20 & Dip-slope $>$ slope & -0.02 \\
\hline South West & -0.35 & Counter dip-slope & -0.16 \\
\hline West & -0.03 & Fractured zone & -1.03 \\
\hline North West & 0.33 & Land use & \\
\hline Lithology & & Forest & 1.54 \\
\hline Quartzite, schist & 0.76 & Shrub land & -0.12 \\
\hline Marble, schist & -0.26 & Grassland & 0.88 \\
\hline Meta-sandstone, phyllite & -0.71 & Cultivated land & 0.66 \\
\hline Calc. shale, slate & -1.52 & Barren land & 2.85 \\
\hline Limestone & -1.68 & Constant & -3.64 \\
\hline Granite & -1.60 & & \\
\hline
\end{tabular}

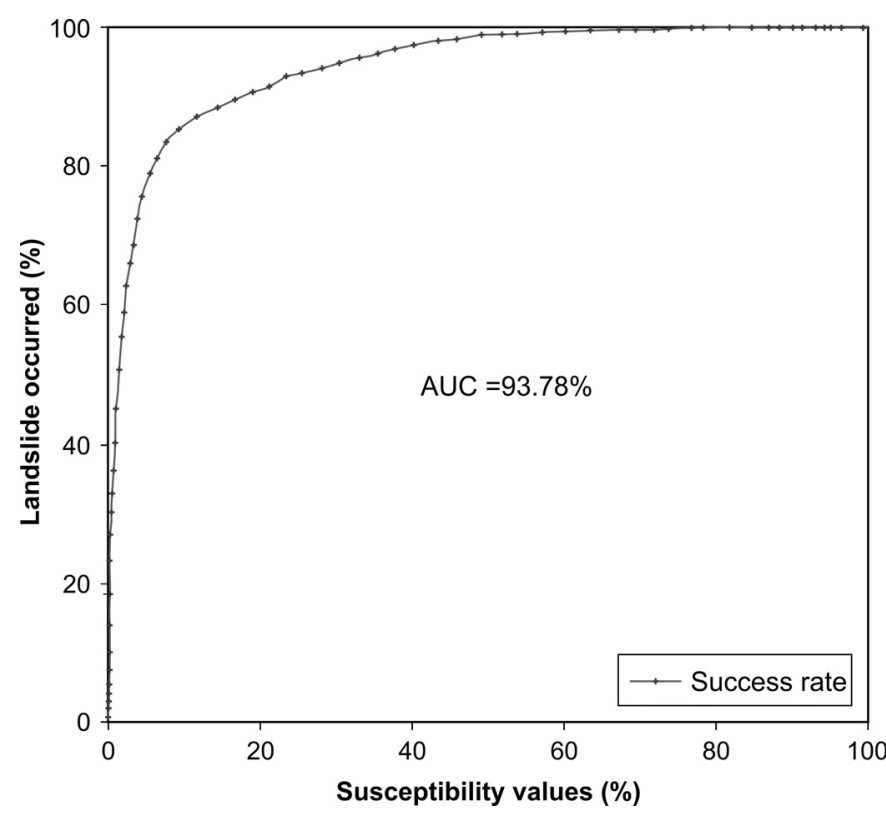

Fig. 7: Validation of landslide susceptibility by success rate.

\section{MODEL INTEGRATION}

Modelling of geological information plays an effective role in the geo-hazard assessment and mitigation (Kajiyama et al. 2004), thus, a workflow has been implemented to integrate the $3 \mathrm{D}$ geomodel and predicted landslide susceptibility in the Lesser Himalaya of central Nepal (Fig. 8). The evaluation of integrated model has revealed that the most susceptible areas confined to schist and quartzite unit which is topographically at uppermost catchments of Agra Khola where cloudburst had been occurred during 19-21 July 1993. In 3D dynamic visualisation, direct relationship of site-conditions geological attributes to the high landslide susceptible areas can be viewed with evidencing the rock strata geometry (i.e. dip-slope domain) has played the significant role in causing the landslides, which is the key aspect of virtual reality.

Overlay of the infrastructure and settlement areas with the susceptibility map enable the assessment of buildings and highways distribution according to landslide susceptibility classes. Results of the prediction model showed that 15.4 per cent of the population lives in highly susceptible landslide zones (Fig. 8). 


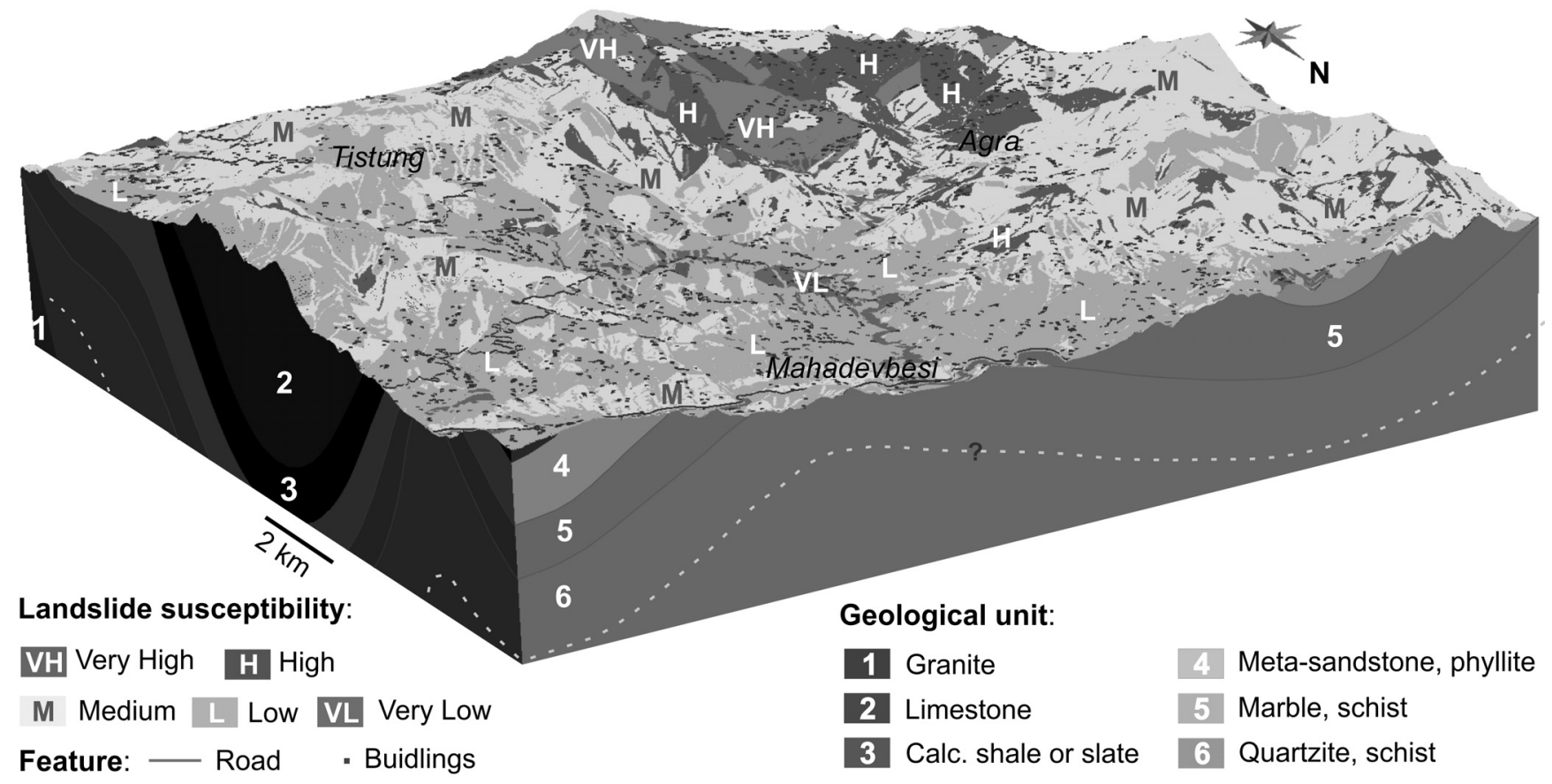

Fig 8: An integrated model of 3D geology and landslide susceptibility.

\section{CONCLUSIONS}

The modelling approach has been succeeded to integrate 3D geology and landslide susceptibility. 3D modelling has provided the new insight in the geological details that computed from optimum database following the implicit approach to interpret the geologic-boundary surfaces when borehole data are not available. The modelled subsurface geometry and properties became key element to visualise landslide susceptibility in the Lesser Himalaya of central Nepal which had obtained through the multivariate technique of logistic regression method. The landslide susceptibility model is found to be appropriate for minimising subjectivity because the results are reproducible. Moreover, field evidences as well as maximum occurrence of landslides in highly susceptible zones proved the precise landslide susceptibility assessment in the prediction modelling. The susceptibility model was evaluated by computing success rate in which AUC is 0.9378 indicating the rate is $93.78 \%$ and thus, the model is valid with prediction accuracy of 0.5 to 1 (total area) and it can be concluded that selected explanatory variables have positive influence on landslide susceptibility.

Spatial overlay of the settlement areas with the susceptibility map showed that 15.4 per cent of the population lives on landslide-prone areas which are at the uppermost catchment of the Agra Khola. Due to the regional significance of predicted landslide susceptibility, the model can be applied to other areas of similar geo-environmental characteristics with exception in site-specific scale. The highly susceptible zones derived in this assessment process can either be avoided or, where this is not possible, appropriate mitigation measures should be implemented that can reduce the impact to an acceptable level.

\section{ACKNOWLEDGMENTS}

The author is grateful to Dr. E. Ismail and another anonymous reviewer for their constructive comments to improve the manuscript.

\section{REFERENCES}

Aleotti, P. and Chowdhury, R., 1999, Landslide hazard assessment: summary review and new perspective. Bull. Eng. Geol. and Env., v. 58, pp. 21-44.

Atkinson, P. M. and Massari, R., 1998, Generalized linear modeling of susceptibility to landsliding in the central Apennines, Italy. Computers and Geosciences, v. 24(4), pp. 373-385.

Baeza, C., Lantada, N. and Moya, J., 2010, Validation and evaluation of two multivariate statistical models for predictive shallow landslide susceptibility mapping of the Eastern Pyrenees (Spain). Environ. Earth Sci., v. 61, pp. 507-523.

Beguería, S. 2006, Validation and Evaluation of Predictive Models in Hazard Assessment and Risk Management. Natural Hazards, 37, pp. 315-329.

Bell, R. and Glade, T., 2004, Quantitative risk analysis for landslides-examples from Bdudalur, NW-Iceland. Nat. Hazard Earth Syst. Sci., v. 4(1), pp. 117-131.

Brabb, E. E. 1984, Innovative approaches to landslide hazard mapping, 4th International Symposium on Landslides, 
16-21 September, Toronto, Canada, pp. 307-324.

Cardinali, M., Carrara, A., Guzzetti, F. and Reichenbach, P., 2002, Landslide hazard map for the Upper Tiber River basin. CNR, Gruppo Nazionale per la Difesa dalle Catastrofi Idrogeologiche, Publication n. 2116, scale $1: 100,000$

Carrara, A. and Pike, R. J., 2008, GIS technology and models for assessing landslide hazard and risk. Geomorphology, v. 94 , pp. $257-260$.

Carrara, A., Cardinali, M., Detti, R., Guzetti, F., Pasqui, V. and Reichenbach, P., 1991, GIS techniques and statistical models in evaluating landslide hazard. Earth Surface Processes and Landforms, v. 16, pp. 427-445.

Carrara, A., Crosta, G. and Frattini, P., 2003, Geomorphological and historical data in assessing landslide hazard. Earth Surface Processes and Landforms, v. 28, pp. 1125-1142.

Cascini, L., 2008, Applicability of landslide susceptibility and hazard zoning at different scales. Engineering Geology, v. 102, pp. 164-177.

Chacón, J., Irigaray, C., Fernández, T. and El Hamdouni, R., 2006, Engineering geology maps: landslides and geographical information systems. Bull. Eng. Geol. Environ., v. 65, pp. 341-411.

Chhetri, M. P. and Bhattarai, D., 2001, Mitigation and Management of Flood in Nepal. Kathmandu, Ministry of Home Affairs.

Chung, C. F. and Fabbri, A. G., 1999, Probabilistic Prediction Models for Landslide Hazard Mapping. Photogrammetric Eng. and Remote Sens., American Soc. for Photogrammetry and Remote Sensing, v. 65(12), pp. 1389-1399.

Chung, C. F. and Fabbri, A. G., 2003, Validation of Spatial Prediction Models for Landslide Hazard Mapping. Kluwer Academic Publishers, Netherlands, Natural Hazards, v. 30, pp. 451-472.

Chung, C. F., Kojima, H. and Fabbri, A. G., 2002, Stability analysis of prediction models for landslide hazard mapping. In: Applied geomorphology: theory and practice, Allison, R. J. (Ed.), Wiley, v. 1-19, London.

Conoscenti, C., Di Maggio, C. and Rotigliano, E. 2008, GIS analysis to assess landslide susceptibility in a fluvial basin of NW Sicily (Italy). Geomorphology, v. 94, pp. 325-339.

Dai, F. C. and Lee, C. F., 2002, Landslide characteristics and slope instability modeling using GIS, Lantau Island, Hong Kong. Geomorphology, v. 42, pp. 213-228.

de Kemp, E. A., 1998, Three-dimensional projection of curvilinear geological features through direction cosine interpolation of structural field observations. Computers and Geosciences, v. 24(3), pp. 269-284.

de Kemp, E. A., 1999, Visualization of complex geological structures using 3-D Bézier construction tools. Computers and Geosciences, v. 25(5), pp. 581-597.
Department of Soil Conservation and Watershed Management, Ministry of Forests and Soil Conservation, Government of Nepal (http://www.dscwm.gov.np/about_dscwm. html).

DHM (Department of Hydrology and Meteorology, Nepal. http://www.dhm.gov.np/.

Fabbri, A. G., Chung, C. F., Cendrero, A. and Remondo, J. 2003, Is prediction of future landslides possible with GIS? Jour. of Nat. Hazards, v. 30, pp. 487-499.

Fawcett, T., 2006, An introduction to ROC analysis. Pattern Recognition Letters. v. 27, pp. 861-874.

Galera, C., Bennis C., Moretti, I. and Mallet, J. L. 2003, Construction of coherent 3D geological blocks. Computers and Geosciences, v. 29(8), pp. 971-984.

Guzzetti, F., Carrara, A., Cardinali, M. and Reichenbach, P., 1999, Landslide hazard evaluation: a review of current techniques and their application in a multi-scale study, Central Italy. Geomorphology, v. 31, pp. 181-216.

Guzzetti, F., Reichenbach, P., Cardinali, M., Galli, M. and Ardizzone, F., 2005, Probabilistic landslide hazard assessment at the basin scale. Geomorphology, v. 72, pp. 272-299.

Hammond, C., Hall, D., Miller, S. and Swetik, P., 1992, Level I Stability Analysis (LISA) Documentation Version 2.0. General Technical Report INT-285, United States Department of Agriculture, Forest Service Intermountain Research Station, USA.

Hervás, J., van Den Eeckhaut, M., Legorreta, G. and Trigila, A., 2013, Landslide Inventory and Susceptibility and Hazard Zoning. Landslide Science and Practice, Springer, v. 1, pp. 1-2.

Jiménez-Perálvarez, J. D., Irigaray, C., El Hamdouni, R. and Chacón, J., 2011, Landslide-susceptibility mapping in a semi-arid mountain environment: an example from the southern slopes of Sierra Nevada (Granada, Spain). Bull. Eng. Geol. Environ., v. 70, pp. 265-277.

Jones, N. L., Budge, T. J., Lemon, A. M. and Zundel, A. K., 2002, Generating MODFLOW grids from boundary representation solid models. Ground Water, v. 40(2), pp. 194-200.

Kajiyama, A., Ikawa, N., Masumoto, S., Shiono, K. and Raghavan, V., 2004, Three-dimensional Geological Modeling by FOSS GRASS GIS "Using Some Field Survey Data". Proceedings of the FOSS/GRASS Users Conference - Bangkok, Thailand.

Kleinbaum, D. G., 1994, Logistic regression: a self learning text. Springer, New York, $282 \mathrm{p}$.

Lemon, A. M. and Jones, N. L., 2003, Building solid models from boreholes and user-defined cross-sections, Computers and Geosciences, v. 29(5), pp. 547-555.

Mallet, J. L., 1992, Discrete smooth interpolation in geometric modeling. Comp. Aided Design, v. 24, pp. 178-191.

Mallet, J. L., 1997, Discrete modeling for natural objects. Mathematical Geology, v. 29(2), pp. 199-219. 
Mallet, J. L. 2002, Geomodeling. Applied Geostatistics, Oxford University Press, New York, 624p.

Mayoraz, R., Mann, C. E. and Parriauz, A., 1992, Threedimensional modelling of complex geological structures: New development tools for creating 3-D volumes. In: Computer modelling of geological surfaces and volumes, Hamilton, D. E. and Jones, T. A. (eds.), Computer Applications in Geology, No 1, pp. 261-271.

Montgomery, D. R. and Dietrich, W. E., 1994, A physically based model for the topographical control on shallow landsliding. Water Resources Research, v. 30, pp. 1153 1171.

Ohlmacher, G. C. and Davis, J. C., 2003, Using multiple logistic regression and GIS technology to predict landslide hazard in northeast Kansa, USA. Engineering Geology, v. 69, pp. 331-343.

Pack, R. T., Tarboton, D. G. and Goodwin, C. N., 1998, Terrain stability mapping with SINMAP, technical description and users guide for version 1.00. Report Number 41140. Terratech Consulting Ltd., Salmon Arm, BC, Canada.

Soeters, R. and van Westen, C. J., 1996, Slope Instability Recognition, Analysis and Zonation. In: Landslides, investigation and mitigation, Turner, A. K. and Schuster, R. L. (eds.), Transportation Research Board, National Research Council, National Academy Press, Washington DC, USA, Special Report 247, pp. 129-177.

Sprague, K. B. and de Kemp, E. A., 2005, Interpretive Tools for 3-D Structural Geological Modelling Part II: Surface Design from Sparse Spatial Data. GeoInformatica, v. 9(1), pp. 5-32.

Stöcklin, J. and Bhattarai, K. D., 1977, Geology of Kathmandu Area and Central Mahabharat Range, Nepal Himalaya, Kathmandu: HMG/UNDP Mineral Exploration Project. Technical Report, New York (Unpublished), 86p.

Süzen, M. L. and Doyuran, V., 2004, A comparison of the GIS based landslide susceptibility assessment methods: multivariate versus bivariate. Environmental Geology, v. 45, pp. 665-679.

van Den Eeckhaut, M., Vanwalleghem, T., Poesen, J., Govers, G., Verstraeten, G. and Vandekerckhove, L., 2006, Prediction of landslide susceptibility using rare events logistic regression: a case-study in the Flemish Ardennes, Belgium. Geomorphology, v. 76, pp. 392-410.

van Westen, C. J., Castellanos, E. and Kuriakose, S. L., 2008, Spatial data for landslide susceptibility, hazard, and vulnerability assessment: An overview. Engineering Geology, v. 102, pp. 112-131.

van Westen, C. J. and Lulie Getahun, F., 2003, Analyzing the evolution of the Tessina landslide using aerial photographs and digital elevation models. Geomorphology, v. 54, pp. 77-89.

van Westen, C. J., Rengers, N., Terlien, M. T. J. and Soeters, R., 1997, Prediction of the occurrence of slope instability phenomena through GIS-based hazard zonation. Geologische Rundschau, v. 86, pp. 404-414.

Varnes, D. J., 1984, Landslide Hazard Zonation: A Review of Principles and Practice. UNESCO Press, Paris, 63 p.

Yesilnacar, E. and Topal, T., 2005, Landslide susceptibility mapping: a comparison of logistic regression and neural networks methods in a moderate scale study, Hendek region (Turkey). Engineering Geology, v. 79, pp. 251266.

Zehner, B. 2011, Constructing Geometric Models of the Subsurface for Finite Element Simulation. Conference of the International Association of Mathematical Geosciences (IAMG 2011), Salzburg, Austria, 5th-9th September 2011.

Zhou, C. H., Lee, C. F., Li, J. and Xu, Z. W., 2002, On the spatial relationship between landslides and causative factors on Lantau Island, Hong Kong. Geomorphology, v. 43, pp. 197-207. 